\title{
Response: "Comment on Record solar UV irradiance in the tropical Andes, by Cabrol et al."
}

\author{
Donat-P. Häder ${ }^{1 *}$, Uwe Feister ${ }^{2}$ and Nathalie A. Cabrol ${ }^{3}$ \\ ${ }^{1}$ Department of Biology, Friedrich-Alexander-Universität Erlangen-Nürnberg, Erlangen, Germany, ${ }^{2}$ Meteorological \\ Observatory Lindenberg-Richard-Aßmann-Observatory, German Meteorological Service, Lindenberg, Germany, ${ }^{3}$ The SETI \\ Institute Carl Sagan Center/NASA Ames Research Center, Moffett Field, Sunnyvale, CA, USA
}

Keywords: record solar UV irradiance, UV index, ozone, UV-B, UV-A, radiative transfer, UV measurement, atmosphere

\section{A commentary on}

Comment on "Record solar UV irradiance in the tropical Andes, by Cabrol et al." by McKenzie, R. L., Bernhard, G., Madronich, S., and Zaratti, F. (2015). Front. Environ. Sci. 3:26. doi: $10.3389 /$ fenvs.2015.00026

OPEN ACCESS

Edited by:

David Delmail,

University of Rennes 1, France

Reviewed by:

Pascal Labrousse,

Université de Limoges, France

*Correspondence:

Donat-P. Häder

donat@dphaeder.de

Specialty section:

This article was submitted to

Environmental Toxicology,

a section of the journa

Frontiers in Environmental Science

Received: 08 September 2015 Accepted: 02 October 2015

Published: 16 October 2015

Citation:

Häder D-P, Feister U and Cabrol NA (2015) Response: "Comment on Record solar UV irradiance in the tropical Andes, by Cabrol et al."

Front. Environ. Sci. 3:68.

doi: 10.3389/fenvs.2015.00068
The record high UV-B values measured in the tropical Andes by Cabrol et al. (2014) are due to several circumstances. The location is within the equatorial belt, at high altitude (5917 $\mathrm{m}$ a.s.l.) and is characterized by an extremely clear and dry atmosphere. The exceptional high values can be explained by two effects: radiation scattering by clouds described by a cloud modification factor (CMF) and negative ozone anomalies (NOA; Feister et al., 2015). An enhancement of solar irradiance of $43 \%$ over cloudless conditions $(\mathrm{CMF}=1.43)$ was reported for Recife, Brazil $\left(8^{\circ} \mathrm{S}\right.$; Piacentini et al., 2011). Enhancements by $50 \%$ in the UV-B irradiance were reported for Girona (Spain, $42^{\circ} \mathrm{N}$ and $100 \mathrm{~m}$ a.s.l.), and for Toowoomba (Australia, $28^{\circ} \mathrm{S}$ and $693 \mathrm{~m}$ a.s.l.; Sabburg and Long, 2004; Sabburg and Calbó, 2009).

Unfortunately, no satellite-based column ozone data are available for the time and location of the ground-based UV-B irradiance measurements. In addition to generally low stratospheric ozone values in the tropics, small-scale negative ozone anomalies need to be considered which result in short-term high UV-B irradiances and high UV-B/UV-A irradiance ratios occurring at highaltitude sites. Both scattering of solar radiation by clouds and the occurrence of NOAs as discussed by Feister et al. (2015) can explain the high UV-B irradiances and the enhanced UV-B/UV-A ratios.

In addition to the potential sources of NOAs discussed by Cabrol et al. (2014), NOAs could be also produced by short-time and small-scale blue jets, as proposed by Feister et al. (2015). These are beams of electromagnetic pulses with narrow spatial extension of about $400 \mathrm{~m}$ on top of Cumulonimbus clouds. They can reach into the stratosphere and extend horizontally to reach diameters of about $3 \mathrm{~km}$ at $35 \mathrm{~km}$ altitude (Mishin, 1997). The consequences are a short initial increase in ozone due to $\mathrm{NO} x$ and $\mathrm{N}_{2} \mathrm{O}$ production followed by a drastic decrease in ozone concentration due to the production of NO which destroys ozone (Winkler and Notholt, 2015). If spread by atmospheric motion, these NOAs can be detected by satellite-based instruments with high pixel resolution.

The Eldonet instruments used in the study by Cabrol et al. (2014) are part of an international network with over 100 instruments deployed in many countries on five continents. McKenzie has used one of these instruments in New Zealand and is a coauthor of a publication which reported the results of measurements covering more than a decade (Häder et al., 2007). The absolute calibration of the instruments was tested in intercalibrations in Garmisch-Partenkirchen 


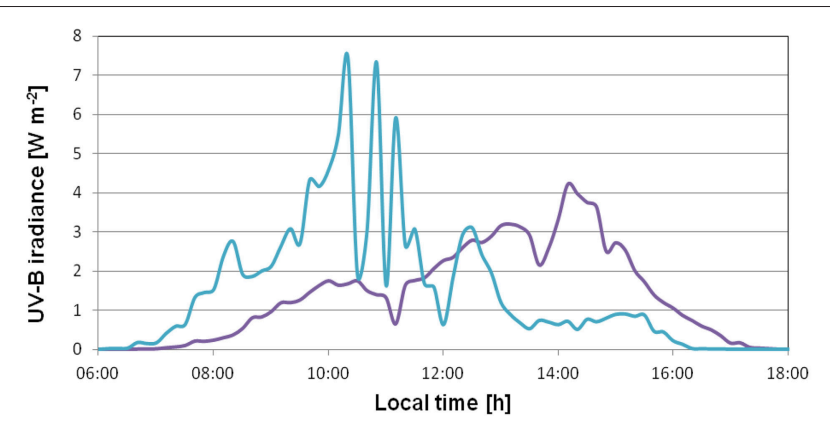

FIGURE 1 | UV-B irradiances measured on 16 January 2004 on Licancabur (22.48 $\mathrm{S} / 67.47^{\circ} \mathrm{W}, 5917 \mathrm{~m}$ a.s.I.; blue) and at Laguna Blanca (22.50 $\mathrm{S} / 67.53^{\circ} \mathrm{W}, 4340 \mathrm{~m}$ a.s.l.; violet).

(Häder et al., 1999) and at the Physikalisch-Meteorologisches Observatorium in Davos, Switzerland in 2006. A calibration coefficient of 1.0044 has been calculated (certificate number 2006/BB14/1). The absolute spectral irradiance of the instruments was calibrated against a light source traceable to the primary irradiance standard of the PTB (Braunschweig, Germany).

One final consideration concerns a potential malfunctioning of an instrument due to the challenging environmental conditions in the high Andes. While the UV-B maxima on the summit were about $4.1 \mathrm{~W} \mathrm{~m}^{-2}$ during the summer, eight instances of extreme irradiances were recorded between 25 November 2003 and 25 January 2004 (Cabrol et al., 2014). A

\section{REFERENCES}

Cabrol, N. A., Feister, U., Häder, D.-P., Piazena, H., Grin, E. A., and Klein, A. (2014). Record solar UV irradiance in the tropical Andes. Front. Environ. Sci. 2:19. doi: 10.3389/fenvs.2014.00019

Feister, U., Cabrol, N., and Häder, D.-P. (2015). UV irradiance enhancements by scattering of solar radiation from clouds. Atmosphere 5, 1211-1228. doi: 10.3390/atmos6081211

Häder, D.-P., Lebert, M., Marangoni, R., and Colombetti, G. (1999). ELDONET European Light Dosimeter Network hardware and software. J. Photochem. Photobiol. B Biol. 52, 51-58. doi: 10.1016/S1011-1344(99)00102-5

Häder, D.-P., Lebert, M., Schuster, M., del Ciampo, L., Helbling, E. W., and McKenzie, R. (2007). ELDONET - a decade of monitoring solar radiation on five continents. Photochem. Photobiol. 83, 1348-1357. doi: 10.1111/j.17511097.2007.00168.x

Mishin, E. (1997). Ozone layer perturbation by a single blue jet. Geophys. Res. Lett. 24, 1919-1922. doi: 10.1029/97GL01890

Piacentini, R. D., Salum, G. M., Fraidenraich, N., and Tiba, C. (2011). Extreme total solar irradiance due to cloud enhancement at sea level of the NE Atlantic Coast of Brazil. Renew. Energ. 36, 409-412. doi: 10.1016/j.renene.2010.06.009 strong argument against a malfunctioning of an instrument being the source for the extreme values is the fact that on several occasions maximal values were found in one instrument located on Licancabur (5917 $\mathrm{m}$ a.s.l.) and several hours later by a second instrument positioned at Laguna Blanca $10 \mathrm{~km}$ to the east ( $4340 \mathrm{~m}$ a.s.l.) with somewhat lower UV-B irradiances due to the lower altitude. Figure 1 shows the extreme UV-B irradiances recorded on 15 January 2004 for the two locations. The irradiance patterns indicate partly cloudy conditions, which are a prerequisite for the enhanced CMFs, and maxima in the morning between 10 and $11 \mathrm{~h}$ for Licancabur and maximal values between 14 and $15 \mathrm{~h}$ for the Laguna Blanca instrument. This result (and several others, not shown here) makes the assumption of an instrument malfunctioning highly improbable.

As a conclusion, the simultaneous occurrence of wavelengthdependent enhanced cloud amplification factors and assumed NOAs at this high altitude site characterized by a close vicinity to the equator and pristine atmospheric conditions may well explain the record high UV-B irradiances reported by Cabrol et al. (2014). A malfunctioning of an instrument can be excluded.

\section{AUTHOR CONTRIBUTIONS}

DH has built and calibrated the Eldonet instruments used on site; UF made the simulation and did the calculation of the cloud amplification factor; NC set up the instruments on the high Andes locations and retrieved them after the measurements were done.

Sabburg, J., and Calbó, J. (2009). Five years of cloud enhanced surface uv radiation measurements at two sites (in the Northern and Southern Hemispheres). Atmos. Res. 93, 902. doi: 10.1016/j.atmosres.2009.05.003

Sabburg, J. M., and Long, C. N. (2004). Improved sky imaging for studies of enhanced uv irradiance. Atmos. Chem. Phys. Discuss. 4, 6213-6238. doi: 10.5194/acpd-4-6213-2004

Winkler, H., and Notholt, J. A. (2015). Model study of the plasma chemistry of stratospheric blue jets. J. Atmos. Solar Terr. Phys. 122, 75-85. doi: 10.1016/j.jastp.2014.10.015

Conflict of Interest Statement: The authors declare that the research was conducted in the absence of any commercial or financial relationships that could be construed as a potential conflict of interest.

Copyright (c) 2015 Häder, Feister and Cabrol. This is an open-access article distributed under the terms of the Creative Commons Attribution License (CC BY). The use, distribution or reproduction in other forums is permitted, provided the original author(s) or licensor are credited and that the original publication in this journal is cited, in accordance with accepted academic practice. No use, distribution or reproduction is permitted which does not comply with these terms. 